\title{
Effective improvement of interface modified strontium titanate based solid oxide fuel cell anodes by infiltration with nano-sized palladium and gadolinium-doped cerium oxide
}

\author{
A. Mohammed Hussain ${ }^{a}, *$, Jens V.T. Høgh ${ }^{a}$, Wei Zhang ${ }^{a}$, Peter Blennow ${ }^{a}$, \\ Nikolaos Bonanos ${ }^{\mathrm{a}}$, Bernard A. Boukamp ${ }^{\mathrm{b}}$ \\ a Department of Energy Conversion and Storage (formerly known as the 'Risø National Laboratory for Sustainable Energy), Technical University of \\ Denmark, Frederiksborgvej 399, 4000 Roskilde, Denmark \\ ${ }^{\mathrm{b}}$ Department of Science and Technology \& MESA+ Institute for Nanotechnology, University of Twente, The Netherlands
}

\section{A R T I C L E I N F O}

\section{Article history:}

Received 20 May 2013

Received in revised form 7 September 2013

Accepted 9 September 2013

Available online 6 October 2013

\section{Keywords:}

Gadolinium-doped ceria (CGO) layer

Spin coating at the interface

Pd-CGO electrocatalyst

Infiltration

Low temperature SOFC anodes

\begin{abstract}
A B S T R A C T
The development of low temperature solid oxide fuel cell (SOFC) anodes by infiltration of Pd/Gd-doped cerium oxide (CGO) electrocatalysts in Nb-doped $\mathrm{SrTiO}_{3}$ (STN) backbones has been investigated. Modification of the electrode/electrolyte interface by thin layer of spin-coated CGO $(400-500 \mathrm{~nm})$ contributed to a significant improvement in performance of the STN backbones and infiltrated electrodes. The improvement is due to the result of CGO enrichment at the interface. The impedance analysis showed that addition of Pd further increased the electrode reaction rate with a factor 10 with respect to the CGO electrocatalysts. Very low electrode polarization resistances of $0.055 \Omega \mathrm{cm}^{2}$ (after excluding the gas diffusion limitation contribution) and $1.2 \Omega \mathrm{cm}^{2}$ at $600{ }^{\circ} \mathrm{C}$ and $400{ }^{\circ} \mathrm{C}$, respectively, have been obtained in $3 \% \mathrm{H}_{2} / \mathrm{H}_{2} \mathrm{O}$. A gradual decrease in polarization resistance was achieved with increasing loading of Pd-CGO electrocatalyst. The microstructural analysis of the infiltrated Pd-CGO electrocatalyst on STN revealed a homogenous coating of Pd and CGO nanoparticles.
\end{abstract}

(c) 2013 Elsevier Ltd. All rights reserved.

\section{Introduction}

The electrochemical conversion of chemical energy by electrooxidizing the fuels (hydrogen or hydrocarbons) using solid oxide fuel cells (SOFCs) is a proven technology for sustainable energy production [1]. Development of efficient anodes, cathodes and electrolytes at low temperature ranges are the primary goal for SOFC technological advancements [2]. The loss associated with the ionic conduction in electrolytes is addressed by reducing the thickness to few microns and by using alternative electrolyte materials with higher ionic conductivities. Gd-doped cerium oxide (CGO) electrolyte based fuel cells with $\mathrm{Ni}-\mathrm{CGO}$ anodes have shown a power density of $1.1 \mathrm{~W} / \mathrm{cm}^{2}$ at $650^{\circ} \mathrm{C}$ and increased 3 times with bimodally integrated anode functional layer, as reported by Kang Taek Lee et al. [3,4]. However, the majority of voltage loss in state of the art SOFCs is associated with the overpotential of the electrodes $[5,6]$.

The development of electrodes with low electrode polarization resistance is required to demonstrate the operation of SOFCs at low temperatures $\left(400-600^{\circ} \mathrm{C}\right)$. Blennow et al. studied the

\footnotetext{
* Corresponding author. Present address: University of Maryland Energy Research Centre (UMERC), 1206 Engineering Lab Building, College Park, ML 20742, USA

E-mail addresses: uzzain@gmail.com, uzzain@umd.edu (A.M. Hussain).
}

redox behaviour and electrochemical characterization of Nb-doped $\mathrm{SrTiO}_{3}$ (STN) as a potential anode for SOFCs [7]. The electrochemical performance of this anode had been improved with the composite of CGO and STN [8]. Marina et al. [9,10] reported the beneficial electrochemical effects of $\mathrm{CeO}_{2}$-modified ( $\left.\mathrm{La}, \mathrm{Sr}\right)(\mathrm{Ti}, \mathrm{Ce}) \mathrm{O}_{3}$ anodes. Electrode/electrolyte modifications at the interface also facilitate an improvement in electrode performance. A thin layer of Y-doped $\mathrm{CeO}_{2}$ on either side of anode and cathode yielded high power density in SOFCs, as reported by Barnett et al. [11]. A change in oxygen transport properties was obtained by insertion of dense $\mathrm{La}_{2} \mathrm{NiO}_{4+\delta}$ in between electrolyte and porous $\mathrm{La}_{2} \mathrm{NiO}_{4+\delta}$ cathode at low temperature $\left(600^{\circ} \mathrm{C}\right)$ [12]. Recently, we reported an improved electrochemical activity for hydrogen oxidation in SOFC anodes with metallic Pd, sputtered at the interface of electrode and electrolyte [13].

The poor electrocatalytic activity of ceramic anodes is the major drawback limiting their application in SOFCs. There are several studies reporting on the possibilities of using $\mathrm{Ce}$-doped $\mathrm{SrTiO}_{3}$ ceramic oxides as potential 'stand-alone' anodes for SOFCs [14-16], however, the studied materials are also limited by catalytic activity. A way to improve anode kinetics in ceramic oxide anodes such as STN is performed by solution infiltration technique resulting in nano-sized electrocatalysts [17]. Nano-structured electrodes will have a very high specific surface area, which is normally associated with high electrochemical performance. Low temperature 
calcination of these infiltrated precursors retains the nanostructure of the percolated electrocatalysts. The possibility of using inexpensive, abundantly available oxides such as tungsten and copper based alternative SOFC anodes by infiltration have recently been reported [18]. Nevertheless, that finding showed higher anode overpotentials, indicative of a need of much better catalysts at low temperature operations of SOFCs $\left(<600^{\circ} \mathrm{C}\right)$. Incorporation of transition metal catalysts in ceramic anodes by infiltration have been widely investigated, in particular Pd addition in doped strontium titanates have shown improved anode performance [19,20-22]. Guntae Kim et al. studied the effect of $\mathrm{Pd}$ and $\mathrm{CeO}_{2}$ in $\mathrm{Y}_{0.04} \mathrm{Ce}_{0.48} \mathrm{Zr}_{0.48} \mathrm{O}_{2}$ and composite $\mathrm{La}_{0.3} \mathrm{Sr}_{0.7} \mathrm{TiO}_{3}-\mathrm{YSZ}$ anodes [21]. Shiwoo Lee et al. reported a cell performance of $780 \mathrm{~mW} / \mathrm{cm}^{2}$ at $800{ }^{\circ} \mathrm{C}$ that was achieved by an addition of $0.5 \mathrm{wt} . \% \mathrm{Pd}$ and 5 wt.\% $\mathrm{CeO}_{2}$ in $\mathrm{La}_{0.3} \mathrm{Sr}_{0.7} \mathrm{TiO}_{3}$ anodes [22]. In a study conducted earlier, we reported the preparation and characterization of efficient ceramic oxide backbones infiltrated with $\mathrm{Ni}$, Pt, Ru or Pd in combination with Gd-doped ceria (CGO) for SOFC anodes [23]. Noble metal catalysts are proven to exhibit excellent catalytic activity for hydrogen oxidation. However, considering the cost and scarcity, it is important to minimize the use of noble metal catalysts. A significant reduction in quantity of noble metals could be made by catalytic precursor infiltration in an electronic conducting ceramic backbone in comparisons to the conventional cermet type anodes [19]. Constituting the majority of the electrocatalyst by cerium oxide ( $90 \mathrm{wt} . \%$ ) with minimal quantity of noble metals reduce the cost considerably. CGO has been shown to have a selflimited grain growth [24], which is advantageous for the stability of nano-structured electrodes. It is to be noted that based on the data reported by $\mathrm{H}$. Kurokawa et al., for a cell operating at a power density of $100 \mathrm{~mW} / \mathrm{cm}^{2}$ the cost of metallic Pd (approximate loading of $1 \mu \mathrm{mol} / \mathrm{cm}^{2}$ ) for $1 \mathrm{~kW}$ stack is $8.62 \mathrm{USD}$, while for metallic Pt and Rh the cost is 53.44 and 24.35 USD [19]. Also, based on the current market situation, the Pd price is about half of the price for $\mathrm{Pt}$, which is known among the noble metals for superior catalytic activity towards hydrogen oxidation.

In this article, we report on the effect of CGO interfacial layer in improving the performance of Pd-CGO electrocatalyst infiltrated STN anodes. In order to modify the electrode/electrolyte interface, thin CGO layers were spin-coated on the $120 \mu \mathrm{m}$ $\mathrm{Sc}_{0.1} \mathrm{Y}_{0.01} \mathrm{Zr}_{0.89} \mathrm{O}_{1.895}$ electrolyte tapes (10Sc1YSZ). The coated tapes were heat treated at low temperatures, resulting in the formation of CGO fluorite type structure. The resulted tapes were printed with STN ink and sintered at high temperatures to form the backbone. The resulted CGO modified STN backbone (CMS) was infiltrated with Pd-CGO electrocatalyst to form an active anode. The high performance in the CMS electrode is due to the enrichment of CGO at the interface, resulting in possible enhancement of triple phase boundary and increase of catalytically active sites for hydrogen oxidation. Although it is certainly not the aim of this study to provide an extensive model for the electrode impedances, the clear change in electrode responses, in relation to the preparation methods, gives clear indications towards the underlying mechanisms. We have tried to present these findings in a tentative model. Further, more detailed, studies are necessary to elucidate these highly interesting features.

\section{Experimental}

\subsection{Spin coating of CGO}

CGO precursor gel, suitable for spin coating, was prepared by dissolving cerium nitrate $\left(\mathrm{Ce}\left(\mathrm{NO}_{3}\right)_{3} \cdot 6 \mathrm{H}_{2} \mathrm{O}\right)$ and gadolinium nitrate $\left(\mathrm{Gd}\left(\mathrm{NO}_{3}\right)_{3} \cdot 6 \mathrm{H}_{2} \mathrm{O}\right)$ in a molar ratio $\mathrm{Ce}: \mathrm{Gd}=0.8: 0.2$ in ethylene glycol. The detailed characterization of the CGO precursor for spin coating is reported elsewhere [25]. Pre-sintered 10Sc1YSZ tapes $\left(6 \times 6 \mathrm{~cm}^{2}\right)$ were washed with ethanol and heat treated at $300^{\circ} \mathrm{C}$ overnight, to remove any organic impurities. A few drops of precursor were added on the tape that was held by a vacuum in the spin coater (Model: WS-400A-8NPP/LITE, Laurell Technologies Corporation). During the spin coating process, initial ejection of excess solvent and subsequent evaporation of the solvents led to a uniform thin coating on the tapes. The thin film deposited on the electrolyte was heat treated at $350^{\circ} \mathrm{C}$ for $1 \mathrm{~h}$ in air, which burned away the binders and formed a CGO layer of $400-500 \mathrm{~nm}$ in thickness.

\subsection{Preparation of Pd-CGO infiltrated anodes}

The STN powders having the nominal composition $\mathrm{Sr}_{0.94} \mathrm{Ti}_{0.9} \mathrm{Nb}_{0.1} \mathrm{O}_{3}$ were synthesized by a wet chemical method reported in our earlier publication [23]. Backbones of STN were prepared by screen printing an in-house fabricated STN ink on both the sides of CGO-coated ScYSZ electrolyte tapes. The symmetrical cell assembly was first sintered in air at $1200^{\circ} \mathrm{C}$ for $4 \mathrm{~h}$ and subsequently pre-reduced at $1000^{\circ} \mathrm{C}$ in $9 \% \mathrm{H}_{2} / \mathrm{N}_{2}$ for $5 \mathrm{~h}$. The cells were cut into smaller squares having an electrode area of $0.25 \mathrm{~cm}^{2}$ for use in the electrochemical set-up.

A $0.75 \mathrm{M} \mathrm{CGO}\left(\mathrm{Ce}_{0.8} \mathrm{Gd}_{0.2} \mathrm{O}_{2-\delta}\right)$ precursor solution was prepared by dissolving cerium nitrate $\left(\mathrm{Ce}\left(\mathrm{NO}_{3}\right)_{3} \cdot 6 \mathrm{H}_{2} \mathrm{O}\right)$ and gadolinium nitrate $\left(\mathrm{Gd}\left(\mathrm{NO}_{3}\right)_{3} \cdot 6 \mathrm{H}_{2} \mathrm{O}\right)$ in water along with a polymer surfactant to improve wetting properties. A precursor solution of $\mathrm{Pd}-\mathrm{CGO}$ was made by mixing $0.60 \mathrm{M}$ palladium nitrate $\left(\mathrm{Pd}\left(\mathrm{NO}_{3}\right)_{2} \cdot 6 \mathrm{H}_{2} \mathrm{O}\right)$ in an already prepared CGO solution. Pd-CGO precursor solution contained $10 \mathrm{wt} . \%$ of Pd and $90 \mathrm{wt} . \%$ of CGO. The STN anodes were prepared by infiltrating a few drops of the precursor solution into the symmetrical cell. Vacuum was applied in order to remove the air bubbles in the porous STN backbone and to facilitate the liquid precursor to coat the backbone surface of the anode homogeneously. After each infiltration, the cells were calcined at $350^{\circ} \mathrm{C}$ for $1 \mathrm{~h}$ in air. The change in weight after the calcination was recorded after each infiltration. The cell was infiltrated with Pd-CGO in 1,6 or 9 repetitive cycles to obtain loadings of $0.4,6$, and $10 \mathrm{wt}$.\% in the CGO modified STN backbone. Similarly, for comparison, unmodified STN backbones were infiltrated three times with a CGO precursor [4 wt.\% loading, denoted: STN CGO(3)] or a Pd-CGO precursor (4.5 wt.\% loading, denoted: [STN Pd-CGO(3)].

\subsection{Microstructural characterization}

FEG-scanning electron microscope (SEM SUPRA 35), operated at $5 \mathrm{kV}$, was employed to characterize the microstructure of the infiltrated anode samples. Few selected samples were also investigated by a transmission electron microscope (TEM) at an accelerating voltage of $300 \mathrm{kV}$ (JEM-3000F). An oxford instruments energy dispersive X-ray spectroscopy (EDS) microanalysis detector with an ultrathin window was used to conduct chemical analysis of samples in scanning transmission electron microscopy (STEM) mode, utilizing the $1 \mathrm{~mm}$ probe size. A $100 \mathrm{~nm}$ thin TEM lamella was prepared by the use of a FIB-SEM H-bar technique in a Crossbeam 1540XB dual focused ion beam (FIB)/SEM (Carl Ziess) using an optimum method [26].

The crystal structure of the synthesized STN powder and sintered STN symmetrical cells on ScYSZ was verified using XRD (Bruker D8 Bragg-Brentano diffractometer) with $\mathrm{Cu} K \alpha$ radiation.

\subsection{Electrochemical characterization}

In this study symmetrical cells have been used. This has the advantage that the electrolyte can be very thin $(120 \mu \mathrm{m}$ in our case), thus strongly reducing its contribution to the electrode dispersion. Measurements under bias in a symmetrical cell are meaningless, 
but for a preliminary screening zero bias measurements are well suited. The study of the response of a single electrode requires the placement of a reference electrode. On a thin electrolyte sheet this requires high precision deposition techniques (see e.g. ref. [27]), or the use of a thick electrolyte pellet with a reference positioned at half height around the cylinder wall [28], which adds a large electrolyte impedance to the electrode dispersion, making it more difficult to obtain reliable data. By keeping the signal voltage low, e.g. $\sim 10 \mathrm{mV}$, the cell assembly may be assumed to behave linearly. By subjecting measurements first to a data validation test, using the Kramers-Kronig rule [29], this requirement is easily tested. It is assumed that both electrodes have an identical response, but when a small difference is observed, average values can be obtained from the CNLS-analysis.

The symmetrical cells were electrically contacted using Pt-paste (Ferro $\mathrm{GmbH}$ ) and a Pt-grid. The cells were heated to $650^{\circ} \mathrm{C}$ in dry $9 \% \mathrm{H}_{2} / \mathrm{N}_{2}$. The gas was then changed to dry $\mathrm{H}_{2}$ and temperature was kept at $650^{\circ} \mathrm{C}$ for $12 \mathrm{~h}$. A Solartron SI 1260 frequency response analyzer was used to measure the impedance of the symmetrical cells. The impedance spectra were measured by applying an amplitude of $5-50 \mathrm{mV}$ (depending on the cell impedance) in the frequency range $1 \mathrm{MHz}$ to $0.1 \mathrm{~Hz}$. The impedance was measured in the temperature range $650^{\circ} \mathrm{C}$ to $350^{\circ} \mathrm{C}$, in $\mathrm{H}_{2} / 3 \% \mathrm{H}_{2} \mathrm{O}$, obtained by humidifying $\mathrm{H}_{2}$ in a water bubbler at room temperature. The partial pressure of oxygen $\left(\mathrm{pO}_{2}\right)$ was measured using a zirconia based oxygen sensor. The EMF values were $-1.131,-1.138,-1.145$ and $-1.147 \mathrm{~V}$ vs. air and the corresponding values of $\mathrm{pO}_{2}$ were $10^{-26}, 10^{-27}, 10^{-29}$, and $10^{-31} \mathrm{~atm}$ at $650,600,550$ and $500^{\circ} \mathrm{C}$, respectively. The impedance spectra were fitted with an equivalent circuit model depending on the number of arcs obtained using the circuit description codes described by Boukamp [30].

\section{Results and discussion}

\subsection{Microstructural characterization}

To investigate the effect of CGO interfacial layer in the unmodified STN backbone, STEM-EDS investigation was performed on the sintered backbone. As shown in Fig. 1, the EDS analysis were performed in four regions $A, B, C$ and D and it is identified that CGO is concentrated in aforementioned regions $B$ and $C$ located adjacent to the interface. Table 1 lists the amount of various elements present in the ceramic backbone deposited on 10Sc1YSZ electrolyte. This weight percentage is helpful in comparing the various elements present in the positions $\mathrm{A}, \mathrm{B}, \mathrm{C}$ and $\mathrm{D}$. No trace of CGO is present at the electrolyte implicating no dissolution of CGO in 10Sc1YSZ electrolyte corresponding to position A. It is also important to note that, no trace of CGO is identified at position $\mathrm{D}$, which is about $4 \mu \mathrm{m}$ above the interface. This observation essentially indicates the concentration of CGO is only at the interface. The amount of CGO in the symmetrical cell is $\sim 0.5 \mathrm{wt} . \%$. The presence of catalytically active CGO at the interface of STN and ScYSZ is believed to be the main reason for the improved electrochemical properties of the STN backbone.

XRD data on the CMS symmetrical cell have not show any CGO related peaks or secondary peaks. This is most likely due to the low quantity of CGO present at the interface of STN and

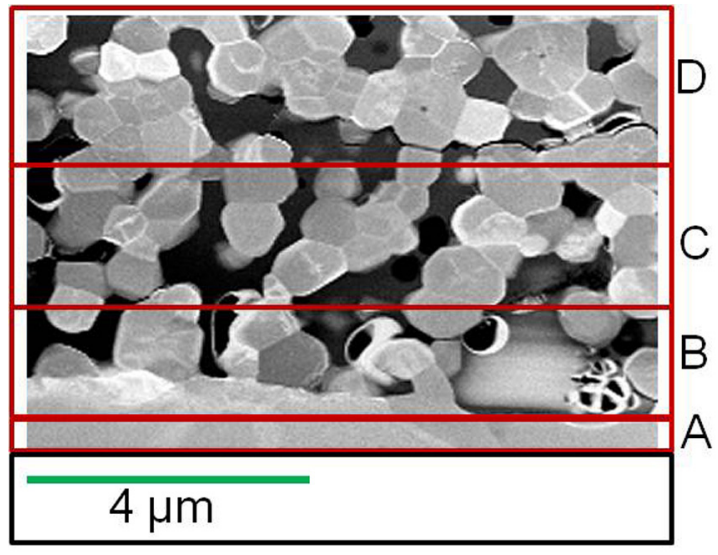

Fig. 1. Bright-field STEM image of CGO modified STN (CMS) backbone. The energy dispersive X-ray analysis is performed in four sections A, B, C and D as shown in the image. The quantitative analysis results of these sections are shown in Table 1.

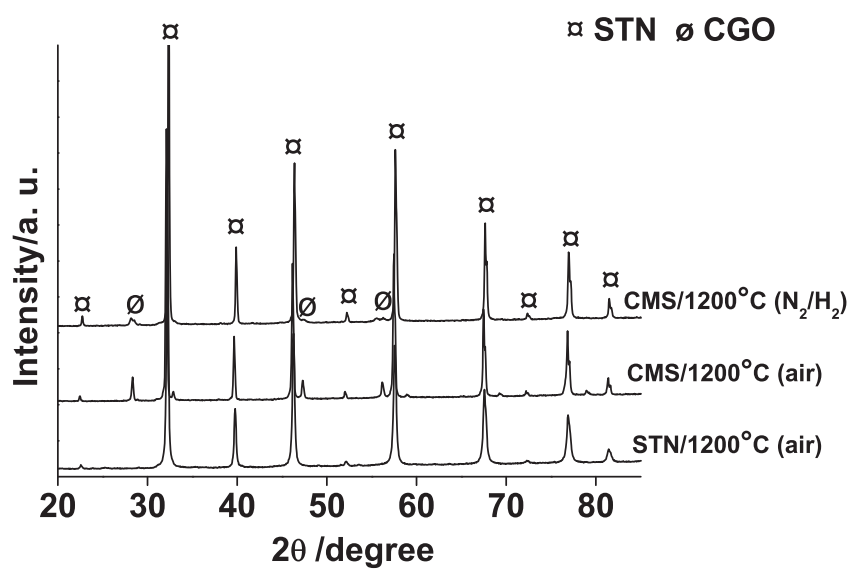

Fig. 2. XRD of STN and STN-CGO (CMS) composite heat treated at the sintering temperature of $1200^{\circ} \mathrm{C}$ in air and reducing gas conditions for $4 \mathrm{~h}$. The peaks of STN and CGO are labelled.

ScYSZ electrolyte in combination with the small grain size (nm range). Moreover, the strong peaks of ScYSZ suppressed the presence of other peaks. In order to investigate the reaction between STN/CGO in detail, known quantity (approximately $8 \mathrm{wt} . \%$ ) of CGO was introduced in STN powder and sintered at $1200^{\circ} \mathrm{C}$ in air and reducing gas $\left(9 \% \mathrm{H}_{2} / \mathrm{N}_{2}\right)$. Shown in Fig. 2 is the XRD data of STN-CGO (CMS) composite sintered in both of these sintering conditions. STN and CGO peaks appear separately for the STN/CGO composite and no detectable traces of secondary peaks were found, which is indicative of no solid-state reaction at this temperature.

Shown in Figs. 3 and 4, respectively are the SEM and TEM micrographs of the CMS backbone infiltrated with a Pd-CGO. The fracture cross sectional SEM image shown in Fig. 3, illustrates the microstructure of the strontium titanate backbone pre-treated with CGO at the electrode/electrolyte interface. The loading of Pd-CGO eletrocatalyst in this backbone sample is approximately $6 \mathrm{wt} . \%$, which is calculated based on the final weight gained in the

Table 1

The EDS quantitative analysis results of CGO modified STN (CMS) backbone shown in Fig. 1.

\begin{tabular}{|c|c|c|c|c|c|c|c|c|}
\hline Positions & Sc [wt.\%] & $\mathrm{Zr}$ [wt.\%] & Y [wt.\%] & $\mathrm{Sr}$ [wt.\%] & Ti [wt.\%] & $\mathrm{Nb}$ [wt.\%] & Ce [wt.\%] & Gd [wt.\%] \\
\hline A & $5.68 \pm 0.33$ & $91.43 \pm 0.55$ & $2.49 \pm 0.46$ & - & - & - & - & - \\
\hline B & $2.7 \pm 0.16$ & $61.10 \pm 0.74$ & $0.82 \pm 0.2$ & $23.12 \pm 0.60$ & $7.17 \pm 0.25$ & $2.99 \pm 0.33$ & $1.88 \pm 0.36$ & $0.22 \pm 0.2$ \\
\hline C & - & - & - & $72.06 \pm 0.66$ & $18.82 \pm 0.39$ & $6.75 \pm 0.45$ & $2.02 \pm 0.45$ & $0.35 \pm 0.27$ \\
\hline D & - & - & - & $76.50 \pm 0.53$ & $16.19 \pm 0.35$ & $7.31 \pm 0.46$ & - & - \\
\hline
\end{tabular}




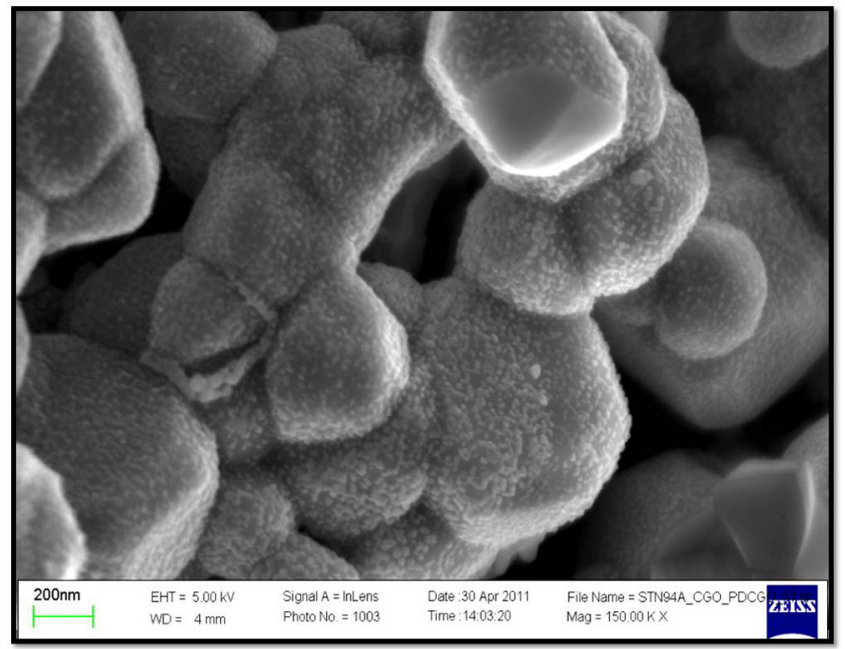

Fig. 3. SEM image of fracture cross section. (a) Pd-CGO infiltrated CGO modified STN (CMS) illustrating the distribution of Pd catalyst on the backbone coated with CGO matrix.

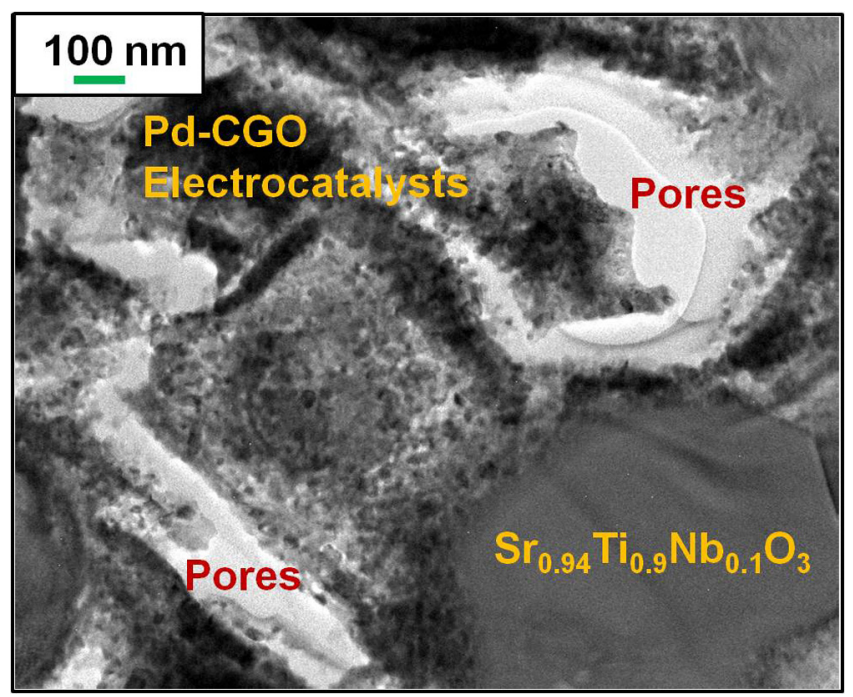

Fig. 4. TEM image of Pd-CGO infiltrated STN modified STN(CMS) backbone depicting STN, pores and the Pd-CGO electrocatalysts. backbone after each successive infiltration steps and the corresponding heat treatments. The crystallites of the strontium titanate are well connected with the grain sizes in the range of $300-700 \mathrm{~nm}$ with random pores ranging from $0.5-5 \mu \mathrm{m}$. The nanostructured $\mathrm{Pd}-$ CGO electrocatalysts on the CMS backbone was closely inspected using TEM. The image obtained from TEM is shown in Fig. 4. The CGO particles are in contact with each other and are observed all over the surface of CMS backbone. The elemental maps in Fig. 5 confirmed the Pd species that are homogeneously dispersed along with the CGO on the strontium titanate grains. Moreover Ce, Gd and Pd have a similar spatial distribution. One of the significant reasons in the improvement of the electrode performance by infiltration of Pd-CGO nanoparticles is this nano-morphology. These electrocatalysts retain the nanostructure due to the low temperature heat treatments. However, it should be noted that, with the increase in the temperature and time of operations, the nanostructured electrocatalysts might grow in to larger agglomerates.

\subsection{Electrochemical characterization}

To provide a good comparison for the improvements with the CGO-modified and infiltrated STN anodes, first the impedances of the bare backbone (STN) and a CGO-modified STN backbone (CMS) were measured. Fig. $6 \mathrm{~A}$ presents the impedances at $600^{\circ} \mathrm{C}$. From this Figure it is obvious that the CMS anode presents already an improvement of a factor of 4-5. The main electrode dispersion can be modelled with a (RQ) circuit (using the circuit description code of ref. [30]). Fig. 6B and C presents the impedances of unmodified STN backbones with 3 successive infiltrations with CGO precursor (B) and a Pd-CGO precursor (C), showing progressive improvements. The equivalent circuits used in the impedance analysis are presented in Fig. 6D. For the infiltrated anodes an additional dispersion is observed, which is interpreted as a 'Gerischer' or 'Chemical' impedance [31], see the lower equivalent circuit in Fig. 6D.

The high frequency part of all four dispersions can be readily assigned to the ionic and grain boundary conductivity of the 10Sc1YSZ electrolyte, as it is independent of the anode type. The bulk ionic conductivity obtained for all samples is presented in Fig. 7, together with previously published results by Irvine et al. [32]. Our values for the ionic conductivity are somewhat higher than those by Irvine et al. and probably identical to the values presented by Laguna-Bercero et al. [33]. Fig. 1b in that publication contains, unfortunately, an incorrect vertical axis, making an

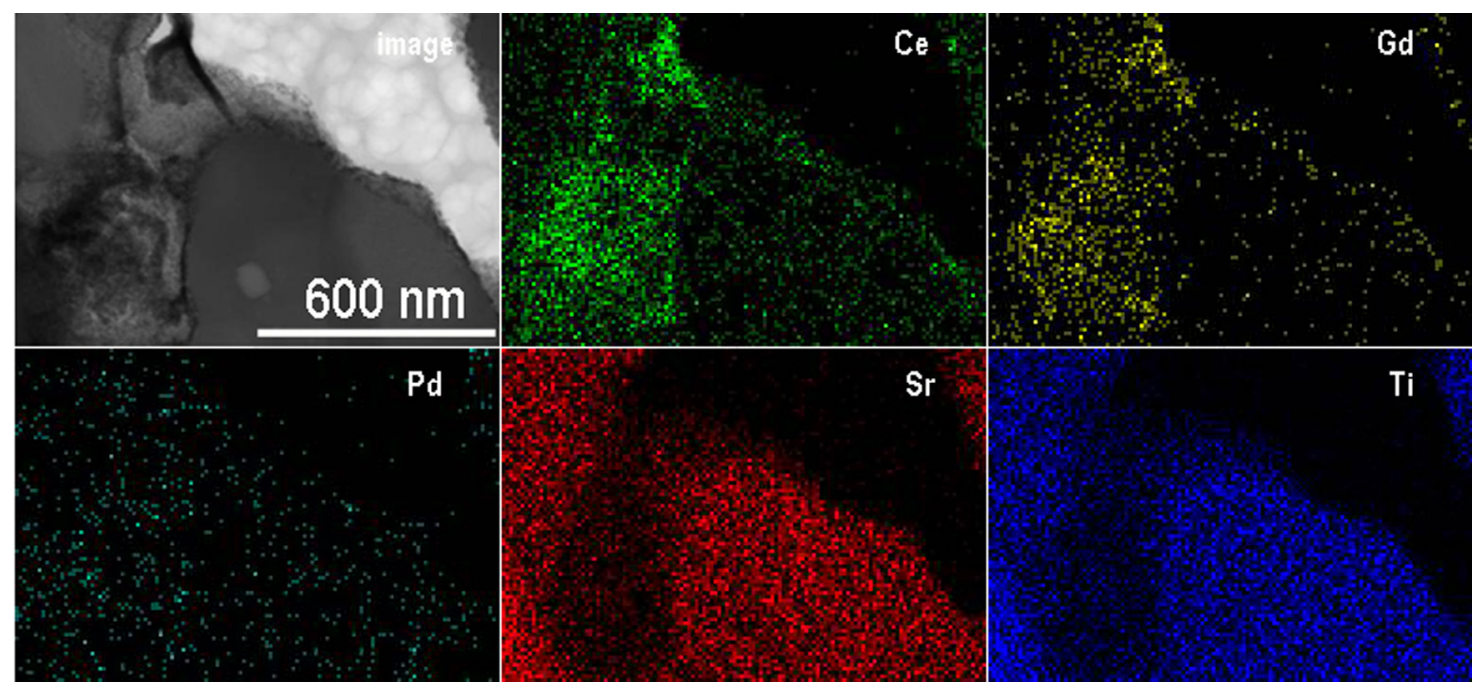

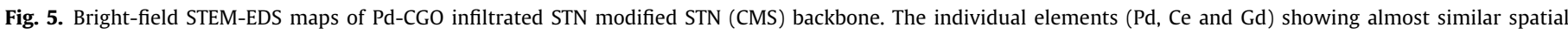
distributions on strontium titanate grains are shown. 

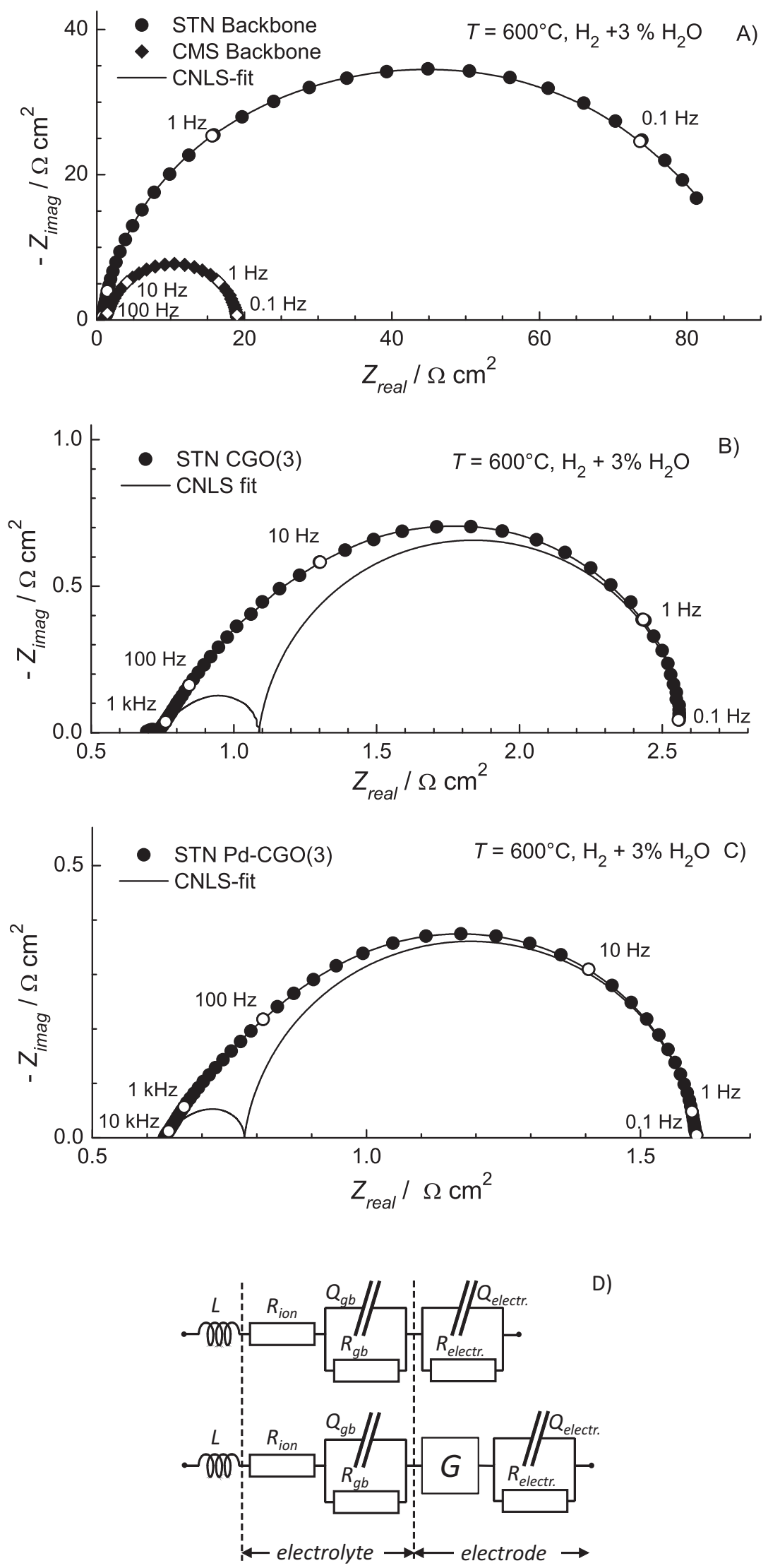

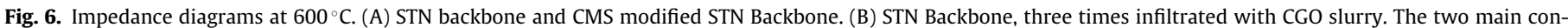

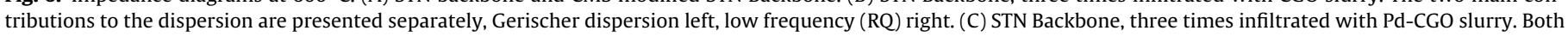
Gerischer and low frequency (RQ) are shown. (D) Equivalent circuit representations used in the CNLS analysis. 


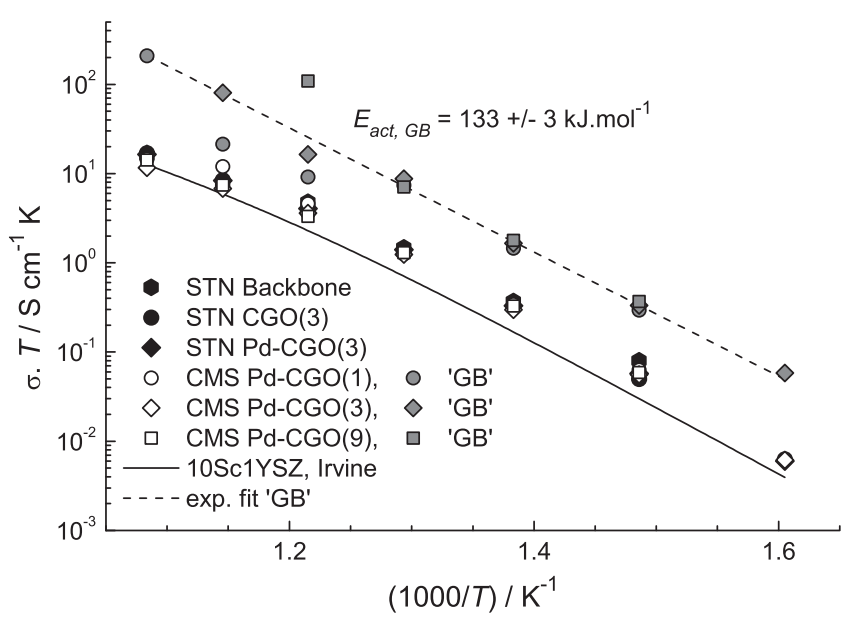

Fig. 7. Assignment of high frequency arcs to ionic conductivity and gran boundary effects of the 10Sc1YSZ electrolyte. Data published by Irvine et al. [32] is also presented.

exact comparison impossible. The second high frequency contribution can be directly ascribed to grain boundary conduction and is also presented in Fig. 7. The corresponding activation energy is quite high with $133 \pm 3 \mathrm{~kJ} \mathrm{~mol}^{-1}$. It is, however, identical to a value of $\sim 133 \mathrm{~kJ} \mathrm{~mol}^{-1}$, as observed by Grosso and Murillo [34] for grain boundary conductivity in $\mathrm{Sc}_{0.1} \mathrm{Ce}_{0.01} \mathrm{ZrO}_{1.9}$ (10Sc1CeSZ).

The presence of a Gerischer dispersion for the two infiltrated anodes is quite remarkable. Fig. 8 presents the Gerischer parameters based on the dispersion relation (admittance):

$Y_{G}(\omega)=Y_{0} \sqrt{K_{a}+j \omega}$

where $K_{a}$ presents a reaction rate. The Gerischer is based on semiinfinite diffusion coupled to a side reaction, e.g. Fick's second law with an additional reaction term [31], leading to a finite dc value:

$Z_{G}(0)=\frac{1}{Y_{0} \cdot \sqrt{K_{a}}}$

Both parameters show very clear thermal activation behaviour, see Fig. 8. The corresponding activation energies are presented in Table 2.

Atangulov and Murygin [35] have developed a model for a porous $\mathrm{H}_{2} / \mathrm{H}_{2} \mathrm{O}$ electrode with a slow absorption reaction, leading to a Gerischer response. Hildenbrand et al., ref. [12], derived a

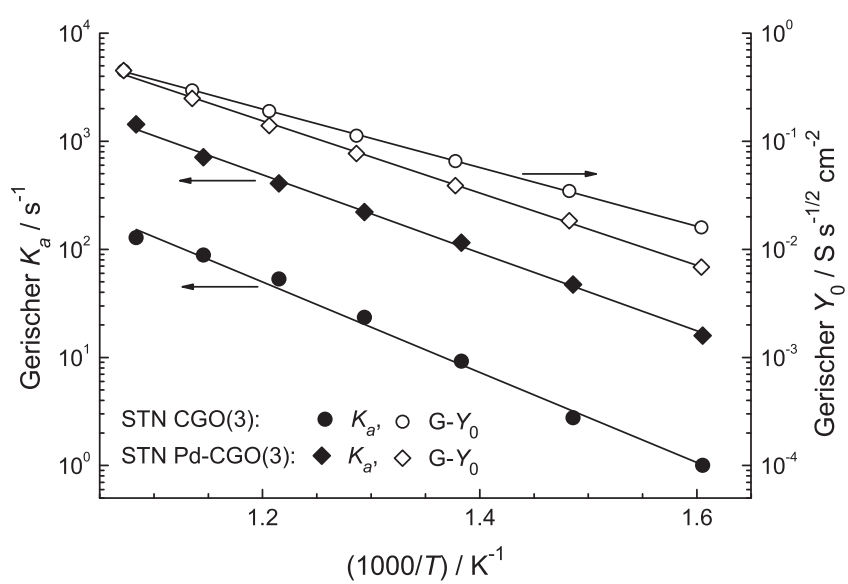

Fig. 8. Arrhenius representation of the Gerischer parameters, $K_{a}$ and $\mathrm{G}-Y_{0}$, for the STN backbone anodes infiltrated three times with a CGO and a Pd-CGO slurry. Activation energies are presented in Table 2 . simple dissociation-adsorption-surface diffusion model for a porous SOFC cathode, also yielding a Gerischer response.

The magnitude of the low frequency capacitances gives an indication of their origin. The apparent capacitance is calculate from the constant phase element (CPE) parameters with the well-known relation, refs. [36,37]:

$C_{a p p}=\frac{\sqrt[n]{R \cdot Y_{0}}}{R}$

where the CPE is expressed as $Y_{C P E}=Y_{0}(j \omega)^{n}$ and $R$ is the parallel resistance. A rough estimate of the internal electrode surface area, based on a grain size of $0.5 \mu \mathrm{m}$ and a porosity of $47 \%$, yields $\sim 71 \mathrm{~cm}^{2}$ per unit electrode area. The ranges of capacitance values for these four anodes are presented in Table 2. An adsorption capacitance (at $0.2 \mathrm{mF} \mathrm{cm}^{-2}$, actual surface area) calculated for the entire electrode thickness $(\sim 50 \mu \mathrm{m})$ would result in a nominal value of $\sim 14 \mathrm{mF} \mathrm{cm}^{-2}$. Hence, this suggests that for the STN and CMS modified anode layer is active. For the CGO-infiltrated anode a much larger value is observed (see Table 2), most likely due to a combination of adsorption and chemical (redox) capacitance of the CGO layer. The addition of Pd lowers the capacitance again, most likely due to a shift of the electrode reaction mechanism to the Pd catalyst particles.

The area specific resistances (ASR's) of the four anodes are presented in Fig. 9. The corresponding activation energies are also presented in Table 2. The CMS modified anode shows almost the same dispersion behaviour as the bare STN backbone anode, but with an approximately five times smaller ASR. The infiltration processes significantly decreases the ASR further. The Pd-CGO(3) anode shows the lowest ASR of these four anodes. The Pd catalyst clearly enhances the electrode reaction rate, as indicated in the more than tenfold increase in the $K_{a}$ reaction rate of the Gerischer impedance with respect to the STN CGO(3) anode. The low frequency capacitance of the STN Pd-CGO(3) anode is about a factor five smaller than found for the STN $\mathrm{CGO}(3)$ anode. This could indicate that, because of a more effective electrode process, the active electrode region is smaller than for the STN CGO electrode.

\subsection{Effect of Pd-CGO infiltration in CGO-modified STN backbone}

The pre-treatment of the electrolyte with a thin CGO layer before applying the STN backbone has a very large impact on the electrode properties for the Pd-CGO infiltrated anodes. The electrode

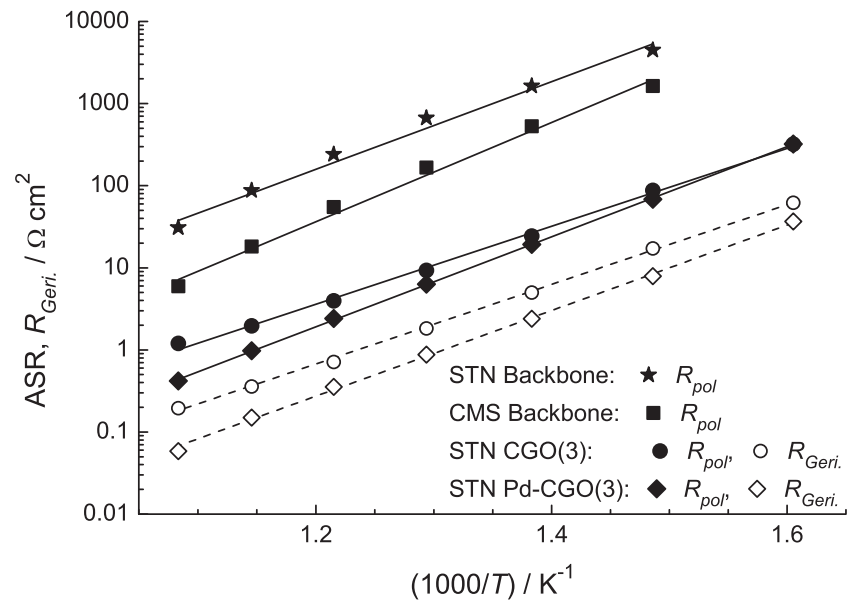

Fig. 9. Area Specific Resistance (polarization) for the STN and CMS modified Backbones and the infiltrated STN Backbones. The dc-contribution of the Gerischer dispersion is also shown. 
dispersions at $600{ }^{\circ} \mathrm{C}$ are presented in Fig. 10. With nine infiltrations an extremely low ASR of $0.055 \Omega \mathrm{cm}^{2}$ at $600^{\circ} \mathrm{C}$ is obtained $\left(1.2 \Omega \mathrm{cm}^{2}\right.$ at $\left.400^{\circ} \mathrm{C}\right)$, see Table 3 . The dispersions were analyzed with the EqC presented in Fig. 10D. The high frequency dispersions (after correction for an inductive contribution of about $0.08-0.2 \mu \mathrm{H}$ ) correspond well with the ionic and grain boundary conductivity of the 10Sc1YSZ electrolyte (see Fig. 7). The inductive correction is shown in Fig. 10 as a dashed line.
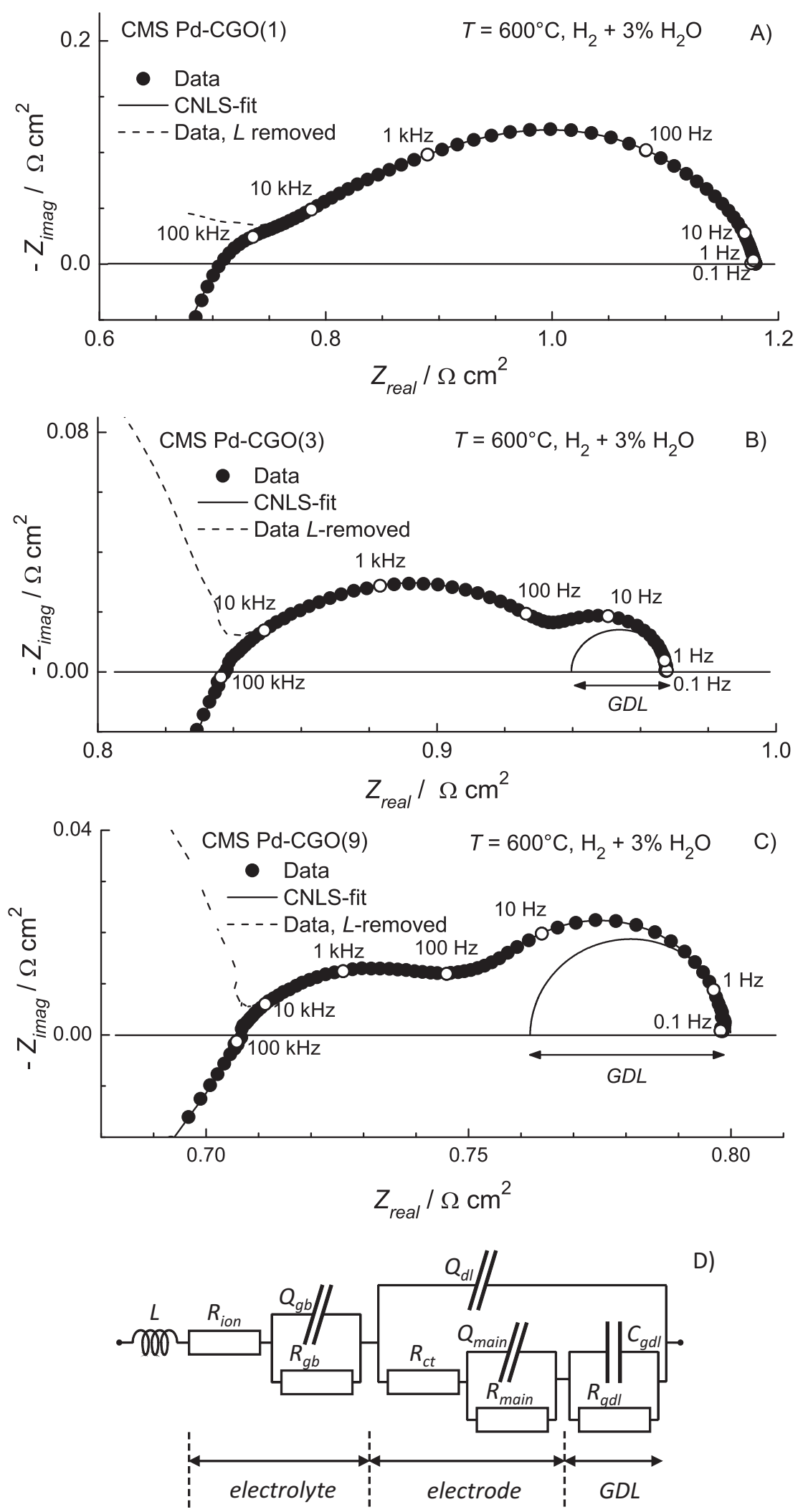

D)

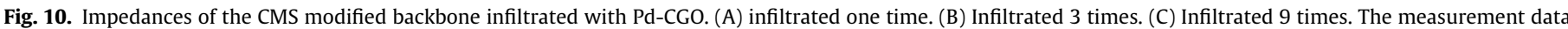

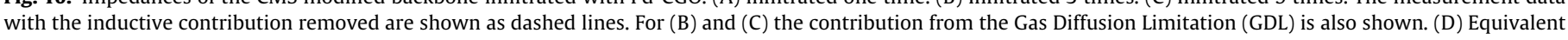
circuit representation used in the CNLS analysis. 
Table 2

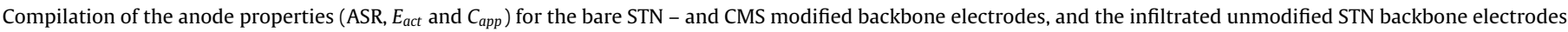

\begin{tabular}{|c|c|c|c|c|c|}
\hline \multirow[t]{2}{*}{ Anode type } & \multirow[t]{2}{*}{$\operatorname{ASR} 600^{\circ} \mathrm{C}\left[\Omega \mathrm{cm}^{2}\right]$} & \multicolumn{3}{|c|}{ Activation energy, $E_{\text {act }}\left[\mathrm{kJ} \mathrm{mol}^{-1}\right]$} & \multirow[t]{2}{*}{ Capacitance, $C_{a p p}\left[\mathrm{mF} \mathrm{cm}^{-2}\right]$} \\
\hline & & Polarization & $\mathrm{G}-K_{a}$ & $\mathrm{G}-Y_{0}$ & \\
\hline STN backbone & 87 & $102 \pm 7$ & - & - & $1.8-5.9$ \\
\hline CMS modified & 18 & $116 \pm 6$ & - & - & $1.7-3.0$ \\
\hline STN CGO(3) & 1.97 & $90.5 \pm 3$ & $80.5 \pm 4$ & $53.0 \pm 0.5$ & $14-35$ \\
\hline STN Pd-CGO(3) & 0.98 & $105 \pm 1$ & $70 \pm 2$ & $65.5 \pm 1.5$ & $2.5-10$ \\
\hline
\end{tabular}

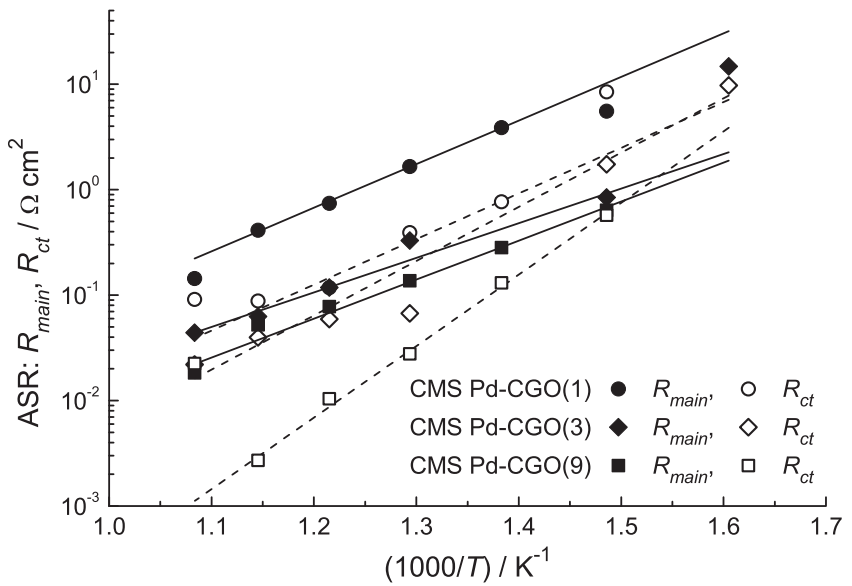

Fig. 11. Compilation of $R_{\text {main }}$ and $R_{c t}$ versus inverse temperature. The drawn lines are best estimates. The error estimates for the data points are relatively high, due to the small contribution to the overall dispersion.

The tentative electrode model EqC is significantly different from those presented in Fig. 6D, but it fits the dispersions of all three CMS Pd-CGO $(x)$ electrodes well. It is based on an ionic path with a charge-transfer like resistance, $R_{c t}$, and an adsorption - surface transfer dispersion, $\left(R_{\text {main }} Q_{\text {main }}\right)$, in parallel with an electronic path coupled through the double layer capacitance, $C_{d l}$, to the electrolyte. The estimated value of about $10-20 \mu \mathrm{F} \mathrm{cm}^{-2}$ for the CMS Pd-CGO(1) anode fits reasonably well with a generally observed value of $0.1-10 \mu \mathrm{F} \mathrm{cm}^{-2}$. Due to the small electrode dispersions with respect to the electrolyte resistance, the error estimates for the CNLS-analysis are often quite large.

The temperature dependences of $R_{c t}$ and $R_{\text {main }}$ are presented in an Arrhenius graph in Fig. 11. The corresponding activation energies are presented in Table 3. Error estimates are omitted in order to keep the figure legible. Clear outliers have been omitted from the least squares fits, presented as lines in Fig. 11. In the dispersion for the 3- and 9-times infiltrated anodes, Fig. 10B and C, a clear contribution from gas diffusion limitation, $\left(R_{g d l} C_{g d l}\right)$, is indicated. As expected this dispersion is virtually temperature independent, see the open symbols in Fig. 12. For the CSM Pd-CGO(1) anode the GDL is only noticeable at $650^{\circ} \mathrm{C}$. The area specific resistances, ASR, are presented in the Arrhenius graph of Fig. 12. For the CSM Pd-CGO(1) anode a single activation process is observed (straight line), the ASR's of the other two anodes show a curvature, which is due to a change over from a $R_{c t}$ controlled dispersion at lower temperatures

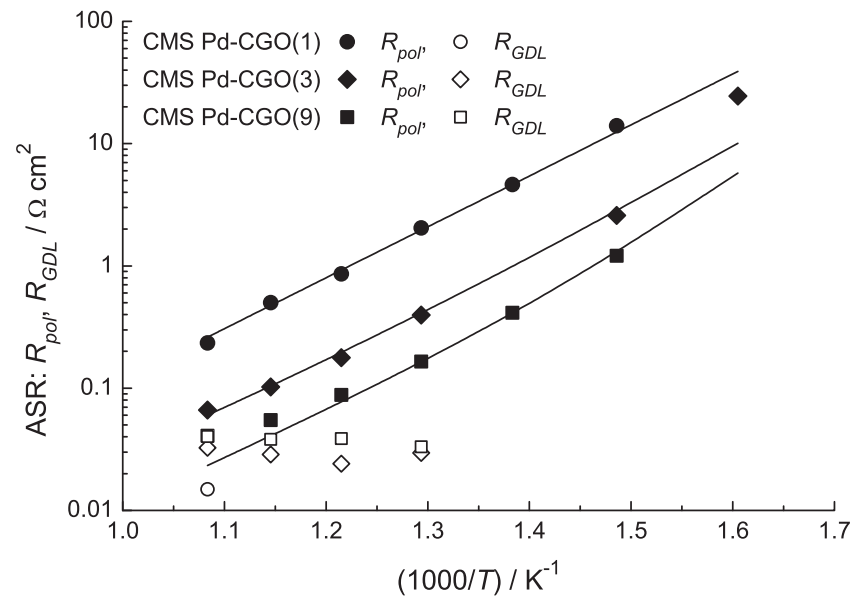

Fig. 12. Compilation of the specific area resistance, $R_{p o l}$, for the three Pd-CGO infiltrated CSM backbone anodes. For two electrodes the normalized gas diffusion limitation, $R_{G D L}$, is also presented.

to a $R_{\text {main }}$ controlled one at higher temperatures. In Table 3 the (apparent) activation energies are presented.

The error in the estimation of $C_{\text {main }}$ is quite large. Yet a clear trend as function of number of infiltrations can be observed, but it is impossible to assign this to the increased CGO layer thickness or increased coverage by the Pd catalysts particles. $R_{\text {main }}$ also shows a decrease with increased number of infiltrations.

The difference between the unmodified infiltrated anodes, STN CGO(3) and STN Pd-CGO(3), and the CMS Pd-CGO(3) anode is remarkable. It is clear that the modification by the CGO deposition on the electrolyte has a tremendous effect on the anode properties. Further study is needed to clarify this significant enhancement. But an interesting suggestion could be, among other beneficial effects with the CMS process the electrolyte surface is easily wetted by the infiltration precursor, allowing the deposition of a thin Pd-CGO layer. Due to the (small) electronic conductivity of CGO under strongly reducing conditions, such a layer will enhance the triple phase boundary (TPB) region significantly, facilitating the transfer of $\mathrm{O}=$ to the reaction sites. In the unmodified anodes the transfer is restricted to the TPB at the contact between electrode and electrolyte. A similar effect has been observed for cathodes, where a thin layer of the cathode material applied between electrolyte and porous electrode showed a significant decrease in the ASR and a clear change in the electrode reaction processes $[12,38]$.

Table 3

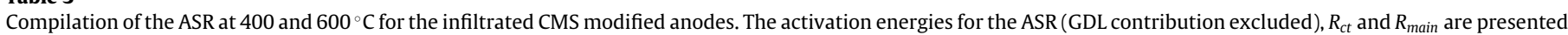
$C_{a p p}$ presents the approximate range for the low frequency capacitance based on $Q_{\text {main }}$.

\begin{tabular}{|c|c|c|c|c|c|c|}
\hline \multirow[t]{2}{*}{ Anode type } & \multirow[t]{2}{*}{$\operatorname{ASR} 400^{\circ} \mathrm{C}\left[\Omega \mathrm{cm}^{2}\right]$} & \multirow[t]{2}{*}{$\operatorname{ASR} 600^{\circ} \mathrm{C}\left[\Omega \mathrm{cm}^{2}\right]$} & \multicolumn{3}{|c|}{ Activation energies $\left[\mathrm{kJ} \mathrm{mol}^{-1}\right]$} & \multirow[t]{2}{*}{ Capacitance, $C_{a p p}\left[\mathrm{mF} \mathrm{cm}^{-2}\right]$} \\
\hline & & & Polarization & $R_{c t}$ & $R_{\text {main }}$ & \\
\hline CMS Pd-CGO(1) & 14 & 0.50 & $83.1 \pm 2.2$ & $81 \pm 15$ & $79 \pm 2.5$ & $0.03-0.05$ \\
\hline CMS Pd-CGO(3) & 2.6 & 0.10 & $(96 \pm 12)$ & $98 \pm 7$ & $64 \pm 8$ & $1-4$ \\
\hline CMS Pd-CGO(9) & 1.2 & 0.055 & $(71 \pm 6)$ & $129 \pm 5$ & $69 \pm 6$ & $3.0-9.8$ \\
\hline
\end{tabular}




\section{Conclusions}

The effect of CGO layer spin coated at the interface of 10Sc1YSZ electrolyte and STN backbone was studied. The presence of CGO at the interface has shown beneficial properties in improving the performance of the anode. Increasing the loading of Pd-CGO by infiltration decreased the polarization resistance of the electrode. A maximum performance was obtained with $10 \mathrm{wt} . \%$ loading of Pd-CGO electrocatlaysts in CGO modified STN backbone. The polarization resistance of the electrodes were obtained by modelling the impedance spectra with tentative equivalent circuits. An efficient anode, with low polarization resistance of $<0.1 \Omega \mathrm{cm}^{2}$ at $600{ }^{\circ} \mathrm{C}$ is presented. The ceramic anodes have an average grain size of $500 \mathrm{~nm}$, the nano-morphology of the Pd-CGO has been demonstrated by microstructural analysis.

\section{Acknowledgements}

The authors wish to thank Ebtisam Abdellahi and Karl T. S. Thydén for TEM sample preparations. The financial support from Department of Energy Conversion and Storage within the project SOFC 400 is greatly acknowledged.

\section{References}

[1] M.L. Perry, T.F. Fuller, A historical perspective of fuel cell technology in the 20th century, J. Electrochem. Soc. 149 (2002) 59-67.

[2] E.D. Wachsman, K.T. Lee, Lowering the temperature of solid oxide fuel cells, Science 334 (2011) 935-939.

[3] K.T. Lee, H.S. Yoon, J.S. Ahn, E.D. Wachsman, Bimodally integrated anode functional layer for lower temperature solid oxide fuel cells, J. Mater. Chem. 22 (2012) 17113-17120.

[4] K.T. Lee, N.J. Vito, H.S. Yoon, E.D. Wachsman, Effect of $\mathrm{Ni}-\mathrm{Gd}_{0.1} \mathrm{Ce}_{0.9} \mathrm{O}_{1.95}$ anode functional layer composition on performance of lower temperature SOFCs, J. Electrochem. Soc. 159 (2012) F187-F193.

[5] R. Barfod, A. Hagen, S. Ramousse, P. Hendriksen, M. Mogensen, Break down of losses in thin electrolyte SOFCs, Fuel Cells 6 (2006) 141-145.

[6] P. Holtappels, J. Bradley, J. Irvine, A. Kaiser, M. Mogensen, Electrochemical characterization of ceramic SOFC anodes, J. Electrochem. Soc. 148 (2001) A923-A929.

[7] P. Blennow, K.K. Hansen, L. Wallenberg, M. Mogensen, Electrochemical characterization and redox behavior of Nb-doped $\mathrm{SrTiO}_{3}$, Solid State Ionics 180 (2009) 63-70.

[8] P. Blennow, K.K. Hansen, L.R. Wallenberg, M. Mogensen, Strontium titanatebased composite anodes for solid oxide fuel cells, ECS Trans. 13 (2008) $181-194$.

[9] O.A. Marina, Novel ceramic anodes for SOFCs tolerant to oxygen, carbon and sulfur, Proceedings in 5th European Solid Oxide Fuel Cell Forum (2002) 481-489.

[10] O.A. Marina, L.R. Pedersen, J.W. Stevenson, Effect of sulfur and hydrocarbon fuels on titanate/ceria SOFC anodes, in: Solid State Energy Conversion Alliance (SECA) Core Technology Peer Review Workshop, Tampa, FL (US), 2005, OSTI identified: 839245.

[11] T. Tsai, S.A. Barnett, Increased solid-oxide fuel cell power density using interfacial ceria layers, Solid State Ionics 98 (1997) 191-196.

[12] N. Hildenbrand, P. Nammensma, D.H.A. Blank, H.J.M. Bouwmeester, B.A. Boukamp, Influence of configuration and microstructure on performance of $\mathrm{La}_{2} \mathrm{NiO}_{4+\delta}$ intermediate-temperature solid oxide fuel cells cathodes, J. Power Sources 238 (2013) 442-453.
[13] A.M. Hussain, J.V. Høgh, W. Zhang, E. Stamate, K.T. Thydén, N. Bonanos, Improved ceramic anodes for SOFCs with modified electrode/electrolyte interface, J. Power Sources 212 (2012) 247-253.

[14] D.J. Cumming, V.V. Kharton, A.A. Yaremchenko, A.V. Kovalevsky, J.A. Kilner, Electrical properties and dimensional stability of Ce-doped $\mathrm{SrTiO}_{3-\delta}$ for solid oxide fuel cell applications, J. Am. Ceram. Soc. 94 (2011) 2993-3000.

[15] D.J. Cumming, J.A. Kilner, S. Skinner, Structural properties of Ce-doped strontium titanate for fuel cell applications, J. Mater. Chem. 21 (2011) 5021-5026.

[16] C. Périllat-Merceroz, G. Gauthier, P. Roussel, M. Huvé, P. Gélin, R. Vannier, Synthesis and study of a Ce-doped La/Sr titanate for solid oxide fuel cell anode operating directly on methane, Chem. Mater. 23 (2011) 1539-1550.

[17] A.M. Hussain, J.V. Høgh, T. Jacobsen, N. Bonanos, Nickel-ceria infiltrated Nbdoped $\mathrm{SrTiO}_{3}$ for low temperature SOFC anodes and analysis on gas diffusion impedance, Int. J. Hydrogen Energy 37 (2012) 4309-4318.

[18] A.M. Hussain, B. Sudireddy, J.V.T. Høgh, N. Bonanos, A preliminary study on $\mathrm{WO}_{3}$-infiltrated $\mathrm{W}-\mathrm{Cu}-\mathrm{ScYSZ}$ anodes for low temperature solid oxide fuel cells, Fuel Cells 12 (2012) 530-536.

[19] H. Kurokawa, L. Yang, C.P. Jacobson, L.C. De Jonghe, S.J. Visco, Y-doped $\mathrm{SrTiO}_{3}$ based sulfur tolerant anode for solid oxide fuel cells, J. Power Sources 164 (2007) 510-518.

[20] G. Kim, S. Lee, J. Shin, G. Corre, J. Irvine, R.J. Gorte, Investigation of the structural and catalytic requirements for high-performance SOFC anodes formed by infiltration of LSCM, Electrochem. Solid-State Lett. 12 (2009) B48-B52.

[21] G. Kim, M.D. Gross, W. Wang, J.M. Vohs, R.J. Gorte, SOFC anodes based on LST-YSZ composites and on $\mathrm{Y}_{0.04} \mathrm{Ce}_{0.48} \mathrm{Zr}_{0.48} \mathrm{O}_{2}$, J. Electrochem. Soc. 155 (2008) B360-B366.

[22] S. Lee, G. Kim, J.M. Vohs, R.J. Gorte, SOFC anodes based on infiltration of $\mathrm{La}_{0.3} \mathrm{Sr}_{0.7} \mathrm{TiO}_{3}$, J. Electrochem. Soc. 155 (2008) B1179-B1183.

[23] A.M. Hussain, J.V. Høgh, W. Zhang, N. Bonanos, Efficient ceramic anodes infiltrated with binary and ternary electrocatalysts for SOFCs operating at low temperatures, J. Power Sources 216 (2012) 308-313.

[24] J.L. Rupp, A. Infortuna, L.J. Gauckler, Microstrain and self-limited grain growth in nanocrystalline ceria ceramics, Acta Mater. 54 (2006) 1721-1730.

[25] P. Plonczak, M. Joost, J. Hjelm, M. Søgaard, M. Lundberg, P.V. Hendriksen, A high performance ceria based interdiffusion barrier layer prepared by spin-coating, J. Power Sources 196 (2011) 1156-1162.

[26] W. Zhang, L.T. Kuhn, P. Jørgensen, K. Thydén, J. Bentzen, E. Abdellahi, B.R. Suddireddy, M. Chen, J.R. Bowen, Transmission electron microscopy specimen preparation method for multiphase porous functional ceramics, Microsc. Microanal. 19 (2013) 501-505.

[27] M. Stodolny, B. Boukamp, D. Blank, F. van Berkel, Cr-poisoning of a $\mathrm{LaNi}_{0.6} \mathrm{Fe}_{0.4} \mathrm{O}_{3}$ cathode under current load, J. Power Sources 209 (2012) 120-129.

[28] B.A. Boukamp, N. Hildenbrand, P. Nammensma, D.H. Blank, The impedance of thin dense oxide cathodes, Solid State Ionics 192 (2011) 404-408.

[29] B.A. Boukamp, A linear Kronig-Kramers transform test for immittance data validation, J. Electrochem. Soc. 142 (1995) 1885-1894.

[30] B.A. Boukamp, Electrochemical impedance spectroscopy in solid state ionics: recent advances, Solid State Ionics 169 (2004) 65-73.

[31] B.A. Boukamp, H.J. Bouwmeester, Interpretation of the Gerischer impedance in solid state ionics, Solid State Ionics 157 (2003) 29-33.

[32] J.T. Irvine, J.W. Dobson, T. Politova, S.G. Martín, A. Shenouda, Co-doping of scandia-zirconia electrolytes for SOFCs, Faraday Discuss. 134 (2007) 41-49.

[33] M. Laguna-Bercero, S. Skinner, J. Kilner, Performance of solid oxide electrolysis cells based on scandia stabilised zirconia, J. Power Sources 192 (2009) 126-131.

[34] R.L. Grosso, E.N.S. Murcillo, Sintering, phase composition and ionic conductivity of zirconia-scandia-ceria, J. Power Sources 233 (2013) 6-13.

[35] R. Atangulov, I. Murygin, Gas electrode impedance with slow adsorption and surface diffusion, Solid State Ionics 67 (1993) 9-15.

[36] T. Jacobsen, B. Zachau-Christiansen, L. Bay, S. Skaarup, in: F.W. Poulsen, N. Bonanos, S. Linderoth, M. Mogensen, B. Zachau-Christiansen (Eds.), Proceedings of the 17th Risø International Symposium on Materials Science, RisøNational Laboratory, Roskilde, Denmark, 1996, p. 29.

[37] C.H. Hsu, F. Mansfeld, Technical note: concerning the conversion of the constant phase element parameter Y-0 into a capacitance, Corrosion 57 (2001) 747-748.

[38] N. Hildenbrand, B.A. Boukamp, P. Nammensma, D.H. Blank, Improved cathode/electrolyte interface of SOFC, Solid State Ionics 192 (2011) 12-15. 